\begin{tabular}{|lccccc|}
\hline $\begin{array}{l}\text { Social Work/Maatskaplike } \\
\text { http://socialwork.journals.ac.za/pub }\end{array}$ & Werk & $\begin{array}{c}\text { Vol } 51 \text { No 1; Issue } \\
\text { doi:http://dx.doi.org/51-1-431 }\end{array}$ & 7 \\
\hline
\end{tabular}

\title{
SOCIAL WORK SERVICES TO VICTIMS OF XENOPHOBIA
}

Dr Marichen van der Westhuizen, Huguenot College, Wellington and research fellow at the Faculty of Practical Theology, University of Stellenbosch, Stellenbosch; Ms Lindy Kleintjes, Social Worker, Department of Social Development, Worcester, Western Cape, South Africa.

\section{Abstract}

The ongoing reports of xenophobic incidents in South Africa require, amongst other things, that the role of the social work profession be explored to ensure that effective services are developed and implemented. This qualitative study explored and described social workers' perceptions regarding the profession's role in service delivery to victims of xenophobia in an attempt to make recommendations in this regard. The findings highlight that there is a need for clear guidelines, that programmes and resources should be available, that social workers must receive education and training related to xenophobia, and that services must be related to the specific needs of the victims. 


\section{SOCIAL WORK SERVICES TO VICTIMS OF XENOPHOBIA}

\section{Marichen van der Westhuizen, Lindy Kleintjes}

\section{INTRODUCTION}

Xenophobia is recognised by the United Nations' Organisation for Education, Science and Culture (UNESCO, 2003) as an ongoing international issue that is influenced by globalisation and migration. The need for preventative actions is emphasised. It is also acknowledged that victims of xenophobia suffer physical, social and emotional trauma that needs to receive attention. In an effort to address this, an international conference was held in Durban (South Africa) in 2001 and followed up in 2011. Issues that were discussed included racism, discrimination, xenophobia and social intolerance. Muigai (2011:4) reflects on these discussions and suggests that, although progress was made in terms of legislation and policies, new innovative efforts are still needed to address this ongoing issue, including renewed focus on services to victims of xenophobia. For this reason the social work profession is challenged with comprehending who its clients are and how to deal with the continuous social changes as a result of globalisation and migration (Husband, 2007; Murji \& Solomos, 2005). Consequently, this article focuses on social workers' experiences and perceptions of services to victims of xenophobia. A background, based on the available literature, will be provided together with the problem statement that guided the research study. The research methodology utilised is provided as a foundation for the discussion of the findings. The article concludes with recommendations for future planning and implementation of services.

\section{LITERATURE REVIEW AND PROBLEM STATEMENT}

In order to provide a background to the problem statement, the literature review places the focus on the phenomenon of xenophobia, followed by a description of the international and local situation. A discussion of the measures in place to address the issue, the impact of xenophobic violence on victims, and the role of the social work profession in this regard concludes the discussion.

The term "xenophobia" refers to a negative attitude towards what is perceived as foreign and an associated fear of foreigners. In this perception, people from other countries (i.e. immigrants and refugees) are treated with mistrust (Morales, Sheafor \& Scot, 2010:233). Guskin and Wilson (2007:15) as well as Landau and Monson (2008:9) explain that immigrants leave their countries of origin voluntarily in a search for better economic and quality-of-life circumstances. Refugees, however, leave their countries of origin based on the violation of human rights (Morales et al., 2010:223). Discrimination based on religion, race, nationality and/or association with certain social groups often leads to a need to find protection from another country. Refugees then leave their countries involuntarily as a result of injustices directed against them (South African Human Rights Commission, 2007).

Xenophobia is described by Hickel (2014:105) in terms of two causal factors, namely economic reasons and social instability, which result in a breakdown in values and 
norms (i.e. moral anomie). In terms of economic reasons, xenophobia is fuelled by the high levels of unemployment. Citizens view immigrants/refugees as a threat to their access to employment opportunities and basic service delivery (Amisi, Bond, Cele, Hinely, ka Manzi, Mwelase, Naidoo, Ngwane, Swarere \& Zvavanhu, 2010:11; Storø, 2011). Describing the link between xenophobic violence and moral anomie, Sichone (2008:257) asserts that "the new South Africa is a good candidate for a society in a condition of anomie." South African history and the social injustices of the past contribute to anxieties about change that manifest in forms of anomie and violence (Haynes, 2012; Landau, 2010). Lorenz (2006:71) furthermore asserts that "the encounter with migrants and refugees is not the cause of fragmentation of social solidarity within societies, but it activates those existing uncertainties in localised, every day, inescapable contexts and interactions." This aspect is also emphasised by Nyamnjoh (2006:1), who explains that globalisation led to anxieties and insecurities that resulted in "an obsession with citizenship and belonging and the re-actualisation of boundaries through xenophobia." Within the South African context, Kamau and Rutland (2008:183-208) summarise the above causes of xenophobia as follows:

- The economy and unemployment - and intense competition for work, housing and other commodities;

- South African perceptions of being superior to other African countries; and

- Exclusive citizenship as a form of nationalism that excludes others.

On an international level, Crush and Ramachandran (2009:10) report on numerous studies that point to an upward trend in xenophobic attacks in countries such as Russia, Denmark, Germany, France, Ireland, Slovakia, Finland and the United Kingdom. Refugees appear to be targeted, leading to brutal attacks.

On local level, immigration and persons seeking protection in South Africa have become more visible during the last decade. Blank and Bucholtz (2011) concur that it is difficult to determine exactly how many immigrants/refugees are living in South Africa because of the large number of illegal immigrants/refugees. The most recent statistics identify 2000000 legal immigrants living and working in South Africa (Statistics South Africa, 2013). It is estimated that approximately 100000 foreigners in South Africa came from Somalia, Malawi, Ethiopia, Zimbabwe and Mozambique (Human Sciences Research Council, 2008), while Gerber (2009) reported that between 6000 to 8000 refugees and illegal immigrants lived in De Doorns and surrounding areas (where various xenophobic incidents were reported) during 2009.

Xenophobic violence against immigrants/refugees in South Africa can no longer be ignored. To illustrate, various newspaper articles reported on violent attacks on foreigners in 2008 (see Raging Mob evicts Zimbabweans, 2008; Thirty-six arrested after two more die in Tshwane, 2008; Recent attacks tip of xenophobic iceberg, 2008; Xenophobic attacks: seven die in one month). These reports described attacks on refugees in Gauteng, KwaZulu-Natal, Mpumalanga, Free State and the Western and Southern Cape. They continued in 2009 in De Doorns (Western Cape) and in 2010 in 
Kya Sands, Johannesburg (Gerber, 2009; Kelly, 2010). Most recently more than 60 foreign-owned shops had to close in 2014 following violent attacks by community members in the Orange Farm and Diepsloot areas of Gauteng. Similar attacks were reported against Somali nationals in KwaZakhele and New Brighton in Port Elizabeth in the Eastern Cape Province (Hickel, 2014:103; Human Rights Watch, 2014). Fabricius (2014) refers to "at least 120 foreign nationals killed in 2011, 140 in 2012 and over 150 in 2013" and asks if xenophobia has become part of the South African way of life.

Measures in place to address xenophobia are based on South African legislation that makes provision for immigrants and refugees, as well as victims of crime. The Refugees Act (Act 130 of 1998, Section 3) describes a refugee who is eligible for protection as a person who fears prosecution in his/her country of origin based on race, religion, nationality, political views or association with a specific social group; when he/she does not receive protection in the country of origin and when he/she left the country of origin and fears to return. The South African government asserted during 2008 that refugees would not be forced to return to their countries (HSRC), 2008).

The Service Charter for Victims of Crime (Constitution of the Republic of South Africa, 1996:3, 7, 8) provides seven rights for all victims of crime, including rights to:

- Be treated with fairness and with respect for dignity and privacy;

- Offer information;

- Receive information;

- Protection;

- Assistance;

- Compensation; and

- Restitution.

These human rights then direct the services that should be available to victims. The Department of Social Development (1997) developed a policy for victims of crime, including victims of xenophobic attacks. In 2007 the Integrated Victim Empowerment Policy, Fourth Draft, was introduced (Department of Social Development, 2007). Although the latter document refers to violence and victimisation as an ongoing problematic situation, it does not identify victims of xenophobia as a priority group. Both these documents describe the importance of a multi-disciplinary team and coordination of services. They do not, however, provide clear guidelines on the role of social workers on ground level in terms of service delivery to victims of xenophobia.

The South African government also reacted on the above-mentioned xenophobic attacks by means of a policy that assists immigrants and refugees to re-integrate into the communities from which they had to flee because of these attacks. But Patel noted recently, however, that the ongoing xenophobic violence "is almost inevitable without the implementation of policies that adequately address the xenophobia in all its ugly complexity" (Patel, 2014:2). 
The impact of xenophobia on victims should be viewed within the context from which they come. Sue (2006:292-293) focuses on the traumatic experiences related to leaving their countries of origin. Refugees in particular were already victims of crime, rape, hunger and/or violence in their countries of origin. The author explains that serious levels of trauma have been experienced prior to the current xenophobic attacks on them. The HSRC (2008:9) reports that refugees and immigrants often had to leave their families behind and that they are alone when faced with physical, emotional and social trauma, and when dealing with challenges such as finding employment and accommodation as well as having to cope with xenophobic attitudes and actions against them. Specific mention is made regarding the fact that immigrants/refugees are often living in crowded and unhealthy living conditions, and that they are vulnerable to becoming victims of exploitation in work situations as they are willing to work far below the minimum wage prescribed by the South African government (HSRC, 2008:9).

The trauma and other challenges experienced by immigrants/refugees related to xenophobia are in line with the social work profession's role in terms of its goals

- To enhance the social functioning of individuals, groups and communities; and

- To address environmental influences that impact on the client system's ability to address needs, insufficient resources and high-risk factors (Timberlake, ZajicekFaber \& Sabatino, 2008:5).

During the outbreaks of xenophobic violence in 2008 the then Minister of Social Development, Zola Skewyiya, asserted that social workers must become involved in the long-term prevention of xenophobia (HSRC, 2008). In 2010 the Consortium for Refugees and Migrants in South Africa (CoRMSA, 2010) provided the Inter-Ministerial Committee on Xenophobic Violence with a set of recommendations consisting of a 10 point action plan. This action plan relates to the role of social workers in terms of the following:

- Strengthen the ability to detect and respond to threats or outbreaks of xenophobic violence;

- Strengthen conflict resolution and prevention mechanisms at community level;

- Strengthen disaster management systems and assistance to displaced persons; and

- Conduct a public information campaign tackling myths and misperceptions about foreign nationals.

The Integrated Victims Empowerment Policy (Department of Social Development, 2007:6-7) does refer to principles relevant in social services to victims of crime in general in terms of human dignity, empowerment, participation and self-determination. However, there is a lack of information pertaining to the role of social workers on ground level. Recent South African studies by the HSRC (2008) and Blank and Buchholz (2011) focused on the phenomenon of xenophobia, but not specifically on the role of the social work profession in this regard. Based on their findings, the HSRC specifically recommended that long-term follow-up services are needed to ensure 
sustainable change. Mnyaka's (2003) study compared the phenomenon of xenophobia with the African principle of ubuntu (i.e. that people are inter-dependent), confirming the previously mentioned anomies as a causal factor for xenophobia. The experiences of xenophobia among immigrant school children in Johannesburg were investigated by Osman (2009). The report by the South African Human Rights Council (2007:27-34) describes the functions of various government departments such as the South African Police Service, Department of Education, Department of Home Affairs, Department of Health and the South African Social Security Agency regarding immigrants, refugees and victims of xenophobia. The Department of Social Development was not included in this description.

\section{Problem statement}

Victims of xenophobia are faced with physical, social and emotional trauma that could be addressed by social workers as part of a multidisciplinary team. Legislation, policy documents and related literature refer to victims of xenophobic violence, causes and consequences of xenophobia, and principles related to services to them. However, no clear description and guidelines could be found as to what social work services should entail. The exact roles of social workers on ground level are therefore unclear. A need to explore the current practices in social work service delivery to victims of xenophobia, as well as social worker's perceptions regarding their role in this regard was identified.

In order to address the research problem, the following research question was formulated to provide a focus for the study: What is the role of the social work profession in service delivery to victims of xenophobia? The research question then directed the formulation of the research goal: To explore and describe the role of the social work profession in service delivery to victims of xenophobia to inform further sustainable development of programmes/projects.

\section{RESEARCH METHODOLOGY}

The qualitative research approach was chosen to ensure that the exploration and description of the research question provide a true reflection of the experiences and perceptions of the social workers (Maree, 2007:50-51). The phenomenological and contextual research designs guided the choices regarding the methodology as follows:

- The phenomenological design (xenophobia): Non-probability sampling method and purposive sampling technique, data collection through semi-structured interviews and a framework to ensure that data analyses led to the identification of themes and subthemes (Groenewald, 2004:4);

- The contextual design (social work profession): Non-probability sampling method and purposive sampling technique, data collection through semi-structured interviews and systematic and thorough data recording (Hom, 2009).

The population of this study consisted of practising, registered social workers in the Western Cape. The criterion for inclusion into the sample was that social workers had to have had experiences with providing services to victims of xenophobia (Royse, 
2008:203-204). Data saturation was observed after 12 semi-structured interviews and data collection was terminated after 15 interviews.

The participants were requested to reflect on and respond to the following request and questions:

- Tell me about your experiences as a social worker when working with victims of xenophobia.

- What do you perceive to be the role of the social work profession regarding services to victims of xenophobia?

- What challenges have you experienced?

- What resources and support do social workers need to deliver effective and sustainable services to victims of xenophobia?

The data were audio recorded and transcribed together with field notes. Ethical aspects addressed were informed consent, voluntary participation, privacy and protection from harm (Graziano \& Raulin, 2007:65-67). This entailed, amongst other things, that the findings were described as a collective story so that individual contributions were not identifiable. This was made possible through analysing the transcripts according to the eight steps for qualitative data analysis by Tesch, as described in Creswell (2009:186).

To ensure the validity of the qualitative data, the researchers made use of Maxwell's five categories of validity in qualitative research (Maxwell, 1992:37-64). Descriptive validity was based on an attempt to accurately describe the data by means of transcripts of verbatim responses. No information was left out or changed, and the use of an independent coder also contributed to descriptive validity. Interpretive validity was ensured by not making interpretations based on the researcher's own judgements, but rather on the use of the transcripts that included both the verbal and non-verbal data to justify interpretations. A literature control was done once the themes and sub-themes were identified through data analysis to ensure theoretical validity. The use of the purposive sampling technique and a thorough description of the implementation of the research methodology ensured transferability of the findings to other applicable contexts. Evaluative validity was achieved by ensuring that the evaluation was based on the findings that emanated from the data-analysis process.

The limitations of this study included the fact that data collection took place over a longer period than expected because social workers found it difficult to find time to participate. They also appeared concerned that they might not answer the questions correctly and needed reassurance that their experiences and perceptions are valid and appreciated. Most of the participants (12) were female; therefore the data mainly reflect the female voice.

\section{RESEARCH FINDINGS}

The participating social workers described their perceptions regarding the causes of xenophobia and provided a description of their experiences when working with victims of xenophobia. They continued to describe their perceptions regarding the role of the 
social work profession in service delivery to victims of xenophobia, including the nature of current services and resources needed to deliver effective services. The themes and sub-themes that illustrate these descriptions will be discussed below. They will be conveyed through verbatim quotes and a literature control.

\section{Theme 1: Perceptions of the causes of xenophobia}

The participants identified being a non-South African, a lack of information, negative perceptions based on gossip, poor service delivery, unemployment and poverty as causes of xenophobia. The following statements attest to these perceptions:

"When people are not from South Africa, crimes are committed against them simply because they are not from here."

"It seems as if these attacks happen because of a lack of information. They [South African communities where xenophobic attacks took place] see these people and think they do not belong here, while our country gave them permission to be here."

"They [South African citizens] blame poor service delivery from, for example, the municipality on the foreigners. They use this as an excuse for the violence."

"I think it happens because people are ignorant about other cultures, also different cultures in South Africa."

"I have witnessed that people will gossip about a specific group of people and then everyone becomes angry and wants revenge. They will say the Nigerians' shops cause poverty among South Africans. Let us break down their shops."

"The local communities feel that foreigners take away job opportunities."

"A main cause is poverty. People are desperate and do not want to compete for jobs and services with people from other countries."

Crush and Ramachandran (2009:12) explain that xenophobia is often the result of stigmatisation and blaming of those who are experienced as foreign for social and economic problems. Yakusho (2009:43) elaborates further and lists four causal factors responsible for the ignorance leading to xenophobia, namely attitude, perceptions, emotions and behaviour towards foreign persons. Poverty, unemployment and a lack of housing were identified by the HSRC (2008:34-37) as causes of xenophobia.

\section{Theme 2: Experiences of working with victims of xenophobia}

The participants' experiences were described in terms of their perceptions of the victims' emotions and attitudes.

\section{Sub-theme 2.1: Emotions experienced by the victims}

Yakusho (2009:37) mentions that the emotional implications of xenophobia are often under-emphasised. The participants' experiences led to the identification of a combination of sadness and anger, disillusionment and fear as feelings that could be ascribed to victims of xenophobia. 
"I experienced that they were sad about what was happening [the xenophobic attacks] and that they were also angry towards the community members who attacked them."

"These victims come from a country where there is a war or where they were already victims of crime. They come to South Africa where they believe everyone is free and then this [xenophobic attacks] happens to them."

"They feel powerless because they do not know who will help them."

"They were very afraid and then the police and other government officials started placing pressure on them that they should leave the camp where they felt protected."

"Some of them were panic-stricken. They were too afraid to leave the camps and also to be forced to go back to their countries. They felt that they were not safe anywhere."

The United Nations (1999:6) identified the emotions of victims of crime (including xenophobia) that need to be addressed as shock, fear, anger, powerlessness and guilt. These emotions make it difficult for the victims to make decisions about their futures.

\section{Sub-theme 2.2: The victims' attitudes regarding the services offered to them}

Related to the negative influence of emotions on decision-making abilities, some participants' experiences were that the victims expected services and that they were reluctant to take some form of ownership of their situation.

"I became aware that they almost fell in a comfort zone. They would not make decisions about their futures."

"They were waiting to be helped and almost acted as if the community owed them something."

Zitek, Jordan, Monin and Leach (2010:245) discuss the concept of 'entitlement' as an attitude of victims when the outcome of a situation is not in line with expectations. The authors explain that this could be interpreted as selfish behaviour and a low sense of social responsibility. The person feels that he/she deserves something without any personal involvement/responsibility.

\section{Theme 3: Perceptions of the role of the social work profession}

This theme covers social work as a relevant support system, current services, challenges experienced and a lack of clear guidelines for the social work profession's involvement.

\section{Sub-theme 3.1: The social work profession as relevant support system}

The participants perceived the principles of social work as relevant to services to victims of xenophobia. Some, however, felt that the issue of xenophobia is not unique to the social work profession (in line with the emphasis on a multidisciplinary approach - see Department of Social Development, 2007:6-7). Other statements referred to xenophobia as an ongoing reality and that specialised services should be developed. These perceptions are described in the comments below. 
"Social work is based on a respect for each human being. This we must also teach to fellow South Africans. If people from other countries need our help, we must reach out to them."

"If we judge people, we are not social workers. We must reach out and support those in need, irrespective of culture, language and nationality."

"Xenophobia is a national problem and cannot only be addressed by social workers."

"I think it is now at a point where social workers need specialised training to deal with the ongoing xenophobia and that it must be dealt with as a specialised service."

The latter statement was also related to perceptions that social work training should include services to xenophobia victims as a focus point.

"We were not specifically trained to work with foreign cultures. We were taught about the issue of diversity, but it does not help us when we suddenly need to work with traumatised people and we do not know anything about how to handle the language and cultural barriers."

"I think this [referring to xenophobic violence] will go on and if social workers want to help the community to change xenophobic behaviour we need to have proper training."

The ethical guidelines of the South African Council for Social Service Professions (SACSSP, 1978:5-7) specifically refer to the following aspects related to working with victims of xenophobia: social justice, respect for humanity and the responsibility to deliver services to all people in need. Yakusho (2009:54) emphasises the necessity to be well trained to deliver services that are related to the unique needs of victims of xenophobia. In order to be able to effectively implement the ethical guidelines, social work training should therefore also provide social workers with the knowledge and skills to deliver ethically sound and effective services to victims of xenophobia.

\section{Sub-theme 3.2: Description of current services to victims of xenophobia}

Five functions were identified, namely: 1) Support and counselling services; 2) a needs assessments of victims living in the emergency camps; 3) counting the number of victims; 4) ensuring that the people in the emergency camp had legal documents; and 5) developing an Early Childhood Development programme.

"We did provide support, but in my opinion we did not really help the victims."

"We were involved with trauma counselling, but only to those who were affected the most."

"We delivered trauma counselling in the Clinic's mobile caravan. It was impersonal and not private."

"We had to help them to make peace with the fact that they must leave [the refugee camps]." 
"I do not believe trauma can be dealt with in one interview, so I would not call it trauma counselling. But I do think it helped them to have someone to talk to; where they could express themselves and their needs."

"We had to walk around and just ask what type of needs they have. We completed forms while standing."

"We had to count people, provide them with food parcels and so on. It was very unorganised and nobody knew what had to be done."

"We had to see that people had the correct documents and help them with that."

"We played with the children and developed Early Childhood Development programmes."

The descriptions of what was done were also supported by the participants' perceptions on these functions:

"Counting people and looking for correct papers is, in my opinion, not an effective way of doing social work."

"I found it degrading for my profession. We were doing auxiliary work, not social work."

"In my opinion we had no plan. We just went there without knowing what was expected of us."

"It had a negative impact on our other work. We were doing tasks that are not supposed to be done by social workers and meanwhile our other clients received no services."

"The fact that various resources were involved helped. Like the Department of Home Affairs was there, which meant that applications for correct documents went quickly."

The United Nations (1999) handbook for services to victims highlights the importance of emotional support on individual and group level, as well as the availability of various resources. Various authors (cf. Gibson, Ivancevich, Donnelly \& Konopaske, 2006:200; Nelson \& Quick, 2006:217-221; Werner, 2007:317-321) refer to a lack of respect for the social work profession when the role of the social workers is not clear. This leads to expectations that are not related to the purpose and role of the profession. Social workers then become demoralised.

\section{Sub-theme 3.3: Challenges experienced}

The participants reported that 1) service delivery was physically and emotionally draining; 2) other work responsibilities were neglected; 3) it entailed a health risk; 4) the victims did not trust them; 5) a lack of knowledge regarding the victims' language, culture and religion negatively impacted on services; and 6) they were not sure what South African legislative requirements were. The following statements are provided as support: 
"We were not prepared for this and it was quite emotionally draining. We received no debriefing afterwards."

"We worked long hours and became tired."

"We were already overloaded with work and then we had to leave everything and just do this."

"Our other work fell behind and this caused anger in the community. We were helping the foreigners and not them. So this situation actually worsened the xenophobia."

"It was a health risk for us. We were exposed to illnesses and also were afraid and stressed out."

"The victims did not trust us and our motives, which made it difficult to do any real intervention."

"Culture and language and also religion were a difficulty. We were not sure of what is acceptable or not. And we had to make use of translators, which meant we could not have a private conversation and give real support to them."

"We did not know what the law says we are supposed to do; for what we have a mandate."

The descriptions seem to point towards stress among the social workers when working with victims of xenophobia. This could lead to burnout and has a negative influence on the quality of service delivery (Werner, 2007:317-321). Furthermore, culture sensitivity is a core requirement in the social work profession. It entails that social workers must be empowered and skilled to deal with a variety of cultures and traditions (Miley, O'Melia \& DuBois, 2007:70).

\section{Sub-theme 3.4: A lack of clear guidelines for the social work profession's involvement}

The participating social workers expressed that they were unsure of the role of the profession.

"Often we could not really explain what our role is. It was never given to us in a clear way. Xenophobic attacks continue to happen, but we still do not know exactly what we are supposed to do."

"It felt to me that all the role-players came together and wanted to address the situation, but nobody knew exactly what their functions were."

"Training of everyone, also the managers, is needed and it should be in line with policies."

"Before they sent us, the Department should have orientated us and provided us with a clear description of what we were supposed to do. But I think even the managers did not really know; so they could not prepare us." 
The guideline of the Department of Social Development (1997:13) refers to the need for a management team to coordinate and manage services to victims of xenophobia, to ensure inter-department cooperation and communication and the development of networks. Amisi et al. (2010:28) assert that the role of the social work profession in dealing with victims of xenophobia is primarily to coordinate services and to ensure that material needs are being met.

\section{Theme 4: Perceptions of what services should entail}

The following six sub-themes emanated from this theme: assessment of needs as part of emergency services; practical and counselling support; working as part of a multidisciplinary team; emergency plans to be in place; preventative services; and resources needed for effective services.

\section{Sub-theme 4.1: Assessments of needs as part of emergency services}

The participants reported that assessments of needs should form part of the emergency services and described this as follows:

"How can we know what they really need after such a trauma?"

"Emergency services should firstly ensure that the victims are safe, but it is also important to assess what their needs are to help them effectively in the long run.'

This perception is supported by the United Nations (1999:12). Needs should be assessed through observations, incident reports, field research and traditional assessment methods. It is also noted that the outcomes of the assessment should lead to strategies for long-term support. This was also identified by the participants, as illustrated by the following statements:

"Immigrants and refugees need to know that they can request social services and support at any time, not only when attacks take place."

"For real change to take place you need time to walk a road with this person. The whole intervention process should be followed."

\section{Sub-theme 4.2: Practical and counselling support}

The participants identified both practical and counselling support as a role of the social work profession. They referred to individual and group work as methods to address counselling needs.

"We must work with the person's feelings, ensuring that he/she does not feel guilty or inferior. Victims should feel safe and worthy."

"We must be careful not to become administrators; like counting people and looking at their papers, which makes them scared of us."

"We should be a therapeutic resource for them; a place where they can feel safe and accepted." 
"We can work individually to help them work through the trauma. But I think group work can also work well. They can experience a feeling of 'I am not the only one'."

"Our role should focus on restoring self-images and that they can experience some form of social justice and respect for their humanity."

The purpose of counselling should be aimed at creating emotional safety and repairing the sense of self and lead to hope for the future (United Nations, 1999:12). Yakusho (2009:52-53) emphasises cultural sensitivity when counselling and support are provided to victims. The use of translators will therefore entail that the translator must understand the purpose and principles of counselling. The participants also concurred that the victims firstly need to feel safe and that practical support is needed for counselling to be successful.

"They wanted some sign of support. They needed food, a roof over their heads, medical treatment and so on. They first needed to receive material support before they could start to work on their emotional wellbeing."

"They firstly needed to feel safe."

"They were hungry. When you are hungry you have no energy to discuss your feelings."

\section{Sub-theme 4.3: Working as part of a multidisciplinary team}

Baldlock, Manning and Vickerstaff (2007:124-125) refer to Maslow's hierarchy of human needs and explain that basic human needs (i.e. food, shelter, etc.) and safety should be addressed to ensure survival. Thereafter betterment needs could be addressed. The handbook for services to victims of crime (United Nations, 1999:13) supports this viewpoint and adds that a multidisciplinary team is needed to address basic needs. The participants identified community leaders, the South African Police Service, municipalities and various government departments that should join forces when working with victims of xenophobia.

"It really needs manpower, resources and knowledge. We need a team that can ensure this."

"I think we should form a team with community leaders, medical personnel and the police to be able to address all their needs."

"I think the municipality is important to include. The victims need water and hygienic accommodation."

"The police and the Departments of Health and Home Affairs need to work with us. Then we can focus on what we must do, but we know the practical needs of the victims are also addressed. And we can easily refer."

Amisi et al. (2010:28) provide a similar description of role-players needed to address the needs of victims of xenophobia. The Department of Social Development (1997:13) identified the following role-players to be included in the multidisciplinary team: the Department of Social Development as coordinating system together with the 
Departments of Constitutional Reform, Justice, Police Service, Correctional Services, Health and Education and relevant civil organisations. Academic and research institutions are also included as role-players. Miley et al. (2007:377) note that a client system also benefits from teamwork, as more resources are available and different needs could be addressed.

\section{Sub-theme 4.4: Emergency plans to be in place}

The statements below point towards a need to implement the policies that are in place. It appears that, despite the existing policies, the role-players were not ready for the emergency situations.

"There was no Emergency Plan that we all knew. We had to act without a clear plan."

"I think there should be a multidisciplinary team on provincial level in place. They must continuously come together and develop plans and make sure it actually happens. Also, the social workers should be trained to implement the plans. Then the social work profession can live up to its full potential."

"I think it should be part of our yearly operational plans; that communities should be made aware of the rights of foreigners to create a sense of tolerance."

"I want to add that we need a risk plan; like what to do in a case of emergency. Maybe a committee that will ensure that plans, resources and orientation are available when the attacks happen and services are needed."

The Handbook on justice for victims of crime of the United Nations (1999:47) describes the focus areas of awareness programmes in communities where the crimes take place, namely: media campaigns, development of communication opportunities between foreigners and community members, and special events to encourage awareness of different cultures to create tolerance. Yakusho (2009:50) adds that communities often expect immigrants/refugees to reject their own cultural practices and to accept the practices of the host community. The author advises that awareness campaigns should lead to tolerance based on an understanding of each other's differences. This aspect relates to preventative services, described next.

\section{Sub-theme 4.5: Preventative services}

The participants also focused on preventative services in communities as a role of the social work profession.

"Projects should be undertaken to inform communities about the rights of foreigners."

"Projects can also focus on intercultural tolerance; even among the different cultures in our country."

"We need to work in communities to become aware of how everyone can work together, and not to be afraid that people will take your jobs. We should start at schools to help developing correct perceptions and tolerance." 
"Community forums could also be formed to serve as a voice for both the community and the immigrants. They can get to know one another in such a way"

"We must develop programmes with the long-term aim to prevent xenophobia; not just act when there is a crisis. We must start where these attacks began; why did it begin?"

The United Nations (1999:16) highlights the importance of community education as a preventative method. The community must be empowered to address social issues without violence. Weyers (2011:249-299) provides a practice model for community education with the aim of enhancing effective community functioning through the development of individual and collective knowledge, skills, attitudes and behaviours.

\section{Sub-theme 4.6: Resources needed for effective services}

Resources that are needed to fulfil the professions' role and function were identified through the following statements:

"Resources are an obstacle. For example, we did not have transport or emergency funds to obtain things for the Early Childhood Development programmes."

"We need to train more volunteers to help with administrative things, such as the counting of people."

"We need to develop networks with therapists, volunteers and so on. Then they can come and help during emergencies."

"The safety of social workers and volunteers needs to be ensured."

"We need easy access to translators who know what is expected of them."

"Material needs of the victims ... we need resources for accommodation, food, blankets."

The findings described in this section led to the recommendations described in the final section of this article.

\section{RECOMMENDATIONS}

The social work profession's role in addressing xenophobia as a social issue entails prevention by means of community educational programmes. These programmes should focus on providing community members with information on the circumstances and rights of immigrants/refugees, on misperceptions that immigrants/refugees take away opportunities from citizens, and on dealing with conflict without violence. Intercultural tolerance should be an aim of services.

Social workers need training (knowledge, skills and attitudes) to enable them to deal with the needs of immigrants/refugees. This should not only be addressed through learning material related to diversity in social work. Training opportunities in the workplace are needed and services to immigrants/refugees should be included in undergraduate programmes. Specific skills are also needed to utilise translators 
effectively and within an ethically sound context. Specific consideration should be given to develop a specialised service to victims of xenophobia.

Social work to victims of xenophobia should still be in line with the normal intervention process. Assessment should lead to a comprehensive intervention plan that should be implemented and monitored before services are terminated. Services to victims of xenophobia should not only be viewed as an emergency service. Long-term support systems must be in place.

The social work profession's role within the multidisciplinary team should be clearly described. Expectations should be related to social work practice only, as other tasks (e.g. counting people and checking documents) impact negatively on the social workers' relationships with the victims. The social workers should be used, within the multidisciplinary approach, to coordinate services to ensure that resources and victims are linked; to ensure that material needs are met; and to provide support and counselling through individual and group work methods. The latter should focus on the development of a positive sense of self as well as the skills and attitudes that would assist victims to deal with their situations.

Emergency plans should be developed and in place so as to ensure that all role-players are able to respond within their specific expertise fields. This should be managed and monitored by a multidisciplinary team. The emergency plans should make provision for access to resources such as transport and emergency funds for equipment and material support to victims (i.e. food, shelter, clothes, etc.). As part of preparing for dealing with xenophobic violence, all role-players on ground level should receive training and clear guidelines on who must do what.

In conclusion, further research is needed to ensure that this topic is further explored so as to inform the profession regarding service development. Social workers' own perceptions regarding foreigners/immigrants/refugees should be explored and current legislation and policy documents should be analysed and compared to field research regarding the needs of victims of xenophobia.

\section{REFERENCES}

AMISI, B., BOND, P., CELE, N., HINELY, R., KA MANZI, F., MWELASE, W., NAIDOO, O., NGWANE, T., SWARERE, S. \& ZVAVANHU, S. 2010. Xenophobia and civil society: Durban's structured social divisions. Unpublished research study. Durban: University of KwaZulu-Natal.

BALDLOCK, J., MANNING, N. \& VICKERSTAFF, S. 2007. Social policy (3 ${ }^{\text {rd }}$ ed). New York: Oxford University Press.

BLANK, J. \& BUCHHOLZ, S. 2011. Determinants of Xenophobia among South African students in the self-declared rainbow nation. Presentation at 'Conference on Reforming Social Protection Systems in Developing Countries'. Ruhr University, Bochum: Germany. 
CONSORTIUM FOR REFUGEES AND MIGRANTS IN SOUTH AFRICA (CoRMSA). 2010. Recommendations to the Inter-Ministerial Committee on Xenophobic Violence. [Online] Available: http://www.cormsa.org.za/2010/06/21/ cormsa-submits-recommendations-on-xenophobic-violence-to-inter-ministerialcommittee/ (Accessed: 22/07/July 2014].

CONSTITUTION OF THE REPUBLIC OF SOUTH AFRICA. 1996. Act, No 108 of 1996. Pretoria: Government Printer.

CRESWELL, J.W. 2009. Research design: qualitative, quantitative and mixed methods approaches $\left(3^{\text {rd }}\right.$ ed). California: Sage Publications.

CRUSH, J. \& RAMACHANDRAN, S. 2009. Xenophobia, international migration and human development. Human Development Research Paper, 47. Geneva: United Nations.

DEPARTMENT OF SOCIAL DEVELOPMENT. 1997. National policy guidelines for victim empowerment. Pretoria: Government Printer.

DEPARTMENT OF SOCIAL DEVELOPMENT. 2007. Integrated victim empowerment policy: Fourth Draft. Pretoria: Government Printer.

FABRICIUS, P. 2014. Is xenophobia becoming part of the South African way of life? Published in journal of the Institute for Security Studies. [Online] Available: http://www.politicsweb.co.za/politicsweb/view/politicsweb/en/page71654/page71619?oi $\underline{\mathrm{d}=637535 \& \mathrm{sn}=\text { Detail } \& \mathrm{pid}=71616}$ [Accessed: $18 / 07 / 2014$ ].

GERBER, J. 2009. Xenofobie-sweer bars. Die Burger, 18 November 2009.

GIBSON, J.L., IVANCEVICH, J.M., DONNELLY, J.H. \& KONOPASKE, R. 2006. Organisations: behaviour, structure, process $\left(12^{\text {th }}\right.$ ed $)$. New York: McGraw-Hill Higher Education.

GRAZIANO, A.M. \& RAULIN, M. 2007. Research methods: a process of inquiry $\left(6^{\text {th }}\right.$ ed). Boston: Pearson Education, Inc.

GROENEWALD, T.A. 2004. A phenomenological research design illustrated. International Journal of Qualitative Research Methods, 3(1):1-26.

GUSKIN, J. \& WILSON, D.L. 2007. The politics of immigration: questions and answers. New York: AK Press.

HAYNES, N. 2012. Pentecostalism and the morality of money: prosperity, inequality, and religious sociality on the Zambian Copper belt. Journal of the Royal Anthropological Institute, 18(1):123-139.

HICKEL, J. 2014. Xenophobia in South Africa: order, chaos, and the moral economy of witchcraft. Cultural Anthropology, 29(1):103-127.

HOM, J. 2009. Contextual inquiry and field studies in Dey Alexander Consulting creating a quality online user experience. [Online] Available: http://www. deyalexander.com.au/resources/uxd/contextual-inquiry.html [Accessed: 19/04/2011]. 
HUMAN RIGHTS WATCH. 2014. World Report. [Online] Available: http://www. hrw.org/world-report/2014 [Accessed: 18/07/2014].

HUMAN SCIENCES RESEARCH COUNCIL (HSRC). 2008. Citizenship, violence and xenophobia in South Africa: Democracy and governance programmes. Cape Town: HSRC.

HUSBAND, C. 2007. Social work in an ethnically diverse Europe: the shifting challenges of differences. Social Work and Society, 5(3). [Online Journal] Available: http://socwork.net/sws/articel/view/138/507 [Accessed: 18/07/2014].

KAMAU, C. \& RUTLAND, A. 2008. A quasi-experiment on the effects of superordinate categorisation on linking of people from other nations. Psychology and Developing Societies, 20(2):183-208.

KELLY, K. 2010. Warning of xenophobic violence in South Africa after World Cup. The Guardian, 17 May 2010.

LANDAU, L.B. \& MONSON, T. 2008. Displacement, estrangement and sovereignty: reconfiguring state power in urban South Africa. Government and Opposition.

LANDAU, P. 2010. Popular politics in the history of South Africa, 1400-1948. New York: Cambridge University Press.

LORENZ, W. 2006. Perspectives on European social work: from the birth of the nation state to the impact of globalisation. Opladen: Barbara Budrich Publishers.

MAREE, K. 2007. First steps in research. Pretoria: Van Schaik Publishers.

MAXWELL, J.A. 2008. Qualitative research design: an interactive approach $\left(3^{\text {rd }}\right.$ ed). Thousand Oaks: Sage Publications.

MILEY, K.K., O’MELIA, M. \& DUBOIS, B. 2007. Generalist social work practice: an empowering approach $\left(5^{\text {th }} \mathrm{ed}\right)$. Boston: Pearson Publishing.

MNYAKA, M.M.N. 2003. Xenophobia as a response to foreigners in post-apartheid South Africa and Post-exilic Israel: a comparative critique in the light of gospel and Ubuntu ethical principles. Pretoria: University of South Africa. (Unpublished Doctoral Thesis)

MORALES, A., SHEAFOR, B. \& SCOT, M. 2010. Social work a profession of many faces $\left(12^{\text {th }}\right.$ ed). Boston: Pearson Education, Inc.

MUIGAI, G. 2011. Special report on contemporary forms of racism, racial discrimination, xenophobia and related intolerance. Geneva: Palais des Nations.

MURJI, K. \& SOLOMOS, J. 2005. Racialization: studies in theory and practice. Oxford: Oxford University Press.

NELSON, D.L. \& QUICK, J.C. 2006. Organisational behaviour: foundations, realities and challenges. USA: Thomson South-Western.

NYAMNJOH, F.B. 2006. Insiders and outsiders: citizenship and xenophobia in contemporary Southern Africa. London: Zed Books. 
OSMAN, R. 2009. The phenomena of xenophobia as experienced by immigrant learners in inner city schools in Johannesburg. Pretoria: University of South Africa. (Unpublished MED Thesis)

PATEL, K. 2014. Analysis: the ugly truth behind South Africa's xenophobic violence. Wearing our brains on our sleeve, (July):1-3.

RAGING MOB EVICTS ZIMBABWEANS. 2008. [Online] Available: http://www. iol.co.za/index.php [Accessed: 06/09/2008].

RECENT ATTACKS TIP OF XENOPHOBIC ICEBERG. 2008. [Online] Available: http://www.thetimes.co.za/PrintEdition/News/Article/aspx [Accessed: 19/05/2008].

REFUGEES ACT. 1998. South Africa. Act 130 of 1998. Pretoria: Government Printer.

ROYSE, D. 2008. Research methods in social work $\left(5^{\text {th }}\right.$ ed). United States of America: Thomson Brooks/Cole.

SICHONE, O. 2008. Xenophobia. In: SHEPHERD, N. \& ROBINS, S. (eds) New South African Keywords. Johannesburg: Jacana, 255-263.

SOUTH AFRICAN COUNCIL FOR SOCIAL SERVICE PROFESSIONS. 1978. Policy guidelines for course of conduct, code of ethics and rules for social workers. Pretoria: Government Printers.

SOUTH AFRICAN HUMAN RIGHTS COUNCIL. 2007. Open hearings on xenophobia and problems relating to it. South Africa: SAHRC.

STATISTICS SOUTH AFRICA. 2013. Statistical release: mid-year population estimates. Pretoria: Statistics South Africa.

STORØ, C. 2011. Social, health, political and economic trends in Africa. Institute of Development Research and Development Policy, Consultancy Africa Intelligence. Pretoria: CAI's Conflict en Terrorism Unit.

SUE, D. 2006. Multicultural Social Work Practice. New Jersey: John Wiley and Sons Inc.

THIRTY-SIX ARRESTED AFTER TWO MORE DIE IN TSHWANE. 2008. [Online] Available: http://www.capeargus.co.za/index.php. [Accessed: 06/09/2008].

TIMBERLAKE, E.M., ZAJICEK-FABER, M. \& SABATINO, C.A. 2008. Generalist social work practice: a strengths-based problem-solving approach. Boston: Allyn and Bacon.

UNITED NATIONS EDUCATIONAL, SCIENTIFIC AND CULTURAL ORGANISATION (UNESCO). 2003. Fight against racism, discrimination and xenophobia. [Online] Available: http://www.unesco.org/new/en/unesco/ (Accessed: 03/08/2011].

UNITED NATIONS. 1999. Handbook on justice for victims. Geneva: United Nations' Office for Drug Control and Crime Prevention. 
WERNER, A. 2007. Organisational behaviour: a contemporary South African perspective $\left(2^{\text {nd }}\right.$ ed $)$. Pretoria: Van Schaik Publishers.

WEYERS, M.L. 2011. The theory and practice of community work: a South African perspective. Potchefstroom: Xerox, PU for CHE.

XENOPHOBIC ATTACKS: 7 DIE IN ONE MONTH. 2008. [Online] Available http://www.iol.co.za/index.php [Accessed: 06/09/2008].

YAKUSHO, O. 2009. Xenophobia: Understanding the roots and consequences of negative attitudes towards immigrants. The Counselling Psychologist, 37(1):36-66.

ZITEK, E.M., JORDAN, A.H., MONIN, B. \& LEACH, F.R. 2010. Victim entitlement to behave selfishly. Journal of Personality and Social Psychology, 98(2):245-255.

Dr Marichen van der Westhuizen, Huguenot College, Wellington and research fellow at the Faculty of Practical Theology, University of Stellenbosch, Stellenbosch; Ms Lindy Kleintjes, Social Worker, Department of Social Development, Worcester, Western Cape, South Africa. 